\title{
KAJIAN LITERATUR ENDOWMENT EFFECT, LOSS AVERSION DAN STATUS QUO BIAS DALAM PENGAMBILAN KEPUTUSAN
}

\author{
Bayu Laksma Pradana \\ Sekolah Tinggi Ilmu Ekonomi Wiyatamandala \\ bayu@wym.ac.id
}

\begin{abstract}
This paper explains Endowment Effect, Loss Aversion and Status Quo Bias as part of anomalies that Kahneman explained. Endowment effect results as people tend value something more precious when they own the good. Loss Aversion, when people put weight on losing higher than winning. Status Quo Bias, people tendency to stick on default option rather than finding other options. It also provides with evidence and experimental research that had been conducted by researcher focusing in the field of the study. Some examples also discussed to broadening the understanding in the topic.
\end{abstract}

Keywords: Endowment Effect, Loss Aversion, Status Quo

\section{PENDAHULUAN}

Dalam pemikiran ekonomi tradisional, seorang agen ekonomi mendasarkan pemikirannya secara rasional. Rasional dalam arti memiliki keinginan yang stabil dan membuat keputusan secara logis dalam pengambilan keputusannya. Hal ini didokumentasikan dengan baik dan menjadi dasar teori-teori ekonomi moderen seperti Capital Asset Pricing Model yang menilai asset dengan memperhitungkan risiko pasar sebagai proxy, ataupun teori portofolio Markowitz yang memperlihatkan risiko suatu portofolio dapat dikurangi dengan menggabungkan aset dengan variasi korelasi berlainan. Dasar pemikiran rasional ini telah lama menjadi tulang punggung teori ekonomi, namun sejak diangkatnya prospect theory oleh Daniel Kahneman dan Amos Tversky maka teori-teori itu mempunyai oposisi dan puncaknya adalah pada 2008 ketika teori perilaku ekonomi yang banyak membahas tentang bias pikiran mulai diperhitungkan karena teori ekonomi tradisional dinilai gagal memprediksi kejatuhan pasar keuangan di Amerika. Secara historis penyimpangan terhadap pikiran rasional ini sudah banyak didokumentasikan. Dalam bidang pasar modal dan perdagangan saham, temuantemuan seperti tingkat pengembalian negatif di hari senin, ataupun efek mingguan menambah daftar panjang abnormalitas sehingga lebih sering 
dinamakan anomali. Rihard taller (1988) mendokumentasikan anomali winners Curse yang memperlihatkan kejadian pada pasar lelang dimana pemenang mendapatkan barang dengan harga diatas nilai wajar barang tersebut. Hal ini tidak dapat terjadi pada pasar yang didominasi agen ekonomi yang rasional. Keterbatasan informasi dan kemampuan kalkulasi pada akhirnya membatasi rasionalitas (bounded rationality) untuk melakukan penilaian pada barang yang dilelang. Salah satu konsep yang dikembangkan dalam ekonomi adalah bahwa agen ekonomi selalu berusaha memaksimumkan kepuasannya (utility). Mereka memiliki kurva indiference yang berbeda-beda setiap orang bergantung pada masingmasing trade off barang yang menjadi pilihannya. Memaksimumkan kepuasan atau biasa lebih dikenal dalam istilah ekonomi Maximizing Utility akan tercapai bila individu dapat melakukan pilihan yang optimal pada keputusannya. Untuk itu optimization selalu mendapatkan tempat tersendiri dalam ekonomi. Kesulitan melakukan optimisasi adalah adanya kemampuan rasional yang terbatas untuk memilih pilihan yang banyak faktor penentunya. Kendala ini sering disebut sebagai bounded rationality. Bounded Rationality adalah kendala yang sangat nyata dari asumsi ekonomi rasional yang dimilikiki oleh agen ekonomi. Individu untuk memuaskan keinginannya akan secara rasional harus menemukan pilihan yang paling memuaskan atau disebut optimal (optimum choice). Namun untuk memilih pilihan ini seseorang sangat terkendala oleh banyak faktor. Salah satu faktor yang menjadi kendala utilitas maksimum adalah informasi, waktu dan kemampuan kognitif. Bisa dibayangkan seseorang yang menghadapi persoalan sederhana, ambil contoh adalah memilih baju dari lemari yang berisi penuh baju, celana atau lainnya. Pilihan baju mana yang paling cocok dengan cuaca saat ini? Pilihan mana yang paling meningkatkan kewibawaan? dan pertanyaanpertanyaann lainnya menambah kompleksitas berpikir dan akhirnya individu tersebut memakai pakaian yang sering ia gunakan saja. Simon $\mathrm{H}$ berargumen bahwa individu ekonomi akan memiliki kecenderungan lebih memilih melakukan satisfice daripada mengejar optimize. Satisfice adalah keadaan mental yang terpuaskan dengan opsi-opsi yang ada. Dapat terjadi dalam 
proses satisfice bahwa opsi yang paling optimum tidak terjadi. Ini semua terjadi karena kendala bounded rationality. Terdapatnya bounded rationality menyebabkan sebuah masalah dapat menjadi sangat kompleks. Kompleksitas pikiran ini tidak didukung penuh oleh kognitif setiap individu yang cenderung terbatas sehingga kebanyakan dari individu ini memilih short cut pikiran atau jalan pintas untuk memudahkan pemecahan masalah. Short cut atau rules of thumb ini dinamakan heuristic. Heuristic adalah cara-cara sederhana

\section{TELAAH LITERATUR}

\section{Loss Aversion}

Salah satu temuan yang paling awal dari perilaku ekonomi adalah konsep loss aversion. Loss aversion adalah suatu konsep bahwa individu mendapat kebahagiaan ketika mendapatkan uang namun sangat menderita jika kehilangan uang. Misalkan jika seseorang melemparkan sebuah koin terdiri dari kepala dan ekor, lalu akan mendapatkan \$ 150 kalau jatuh pada ekor, lalu membayar \$ 100 jika jatuhnya adalah kepala, akankah anda akan bertaruh pada lempar koin ini? Secara rasional untuk menyelesaikan masalah. Misalnya, seseorang yang akan memilih berbagai pilihan saham, cenderung untuk memilih saham yang sudah diketahuinya atau ia berpikir ia mengetahui seluk beluk saham tersebut. Tulisan ini berusaha menjelaskan kembali tiga heuristic yang sangat terkenal dan telah diobservasi dan didokumentasi selama ini. Loss Aversion, Endowment Effect dan Status Quo Bias. Dalam psikologi heuristic ini lebih dikenal dengan istilah mind bias.

nilai ekspektasi dari taruhan ini adalah +25 ( 50 X 0.5) banyak dari orang yang menolak taruhan ini. Bagaimana jika dilakukan modifikasi pendapatannya menjadi \$ 125 pada ekor, sehingga nilai ekspektasi menjadi $+12,5$. Kenyataannya orang masih saja menolak bahkan ketika nilai ekpektasinya positif. Kejadian lain adalah ketika seseorang mendapatkan keuntungan $2 \%$ pada portofolio sahamnya maka ia akan bahagia sedangkan pada saat turun $2 \%$ mereka sangat tersiksa. 


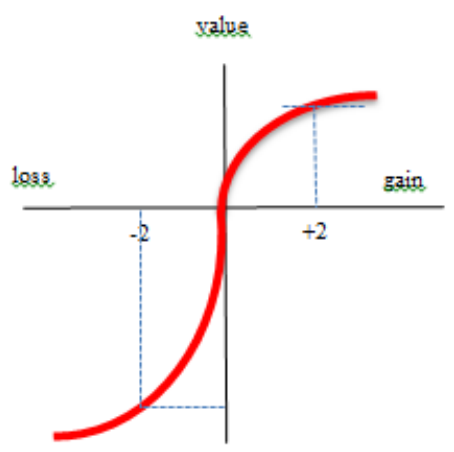

Keadaan asimetri ini yang membuat perilaku keuntungan membuat senang sedangkan rugi diberi nilai 2,5 kali lebih berat dibanding nilai yang diberikan kesenangan. Misalkan jika seseorang wiraniaga elektronik ditawarkan untuk menjual televisi. Televisi dengan merek A dan B. Kedua merek itu diproduksi dari dua perusahaan yang berbeda dan keduanya menjanjikan pembayaran komisi dari setiap penjualan unit yang terjadi. Bagaimana cara kedua perusahaan ini menaikan penjualan mereka? Kedua perusahaan tersebut dapat menaikan komisi mereka. Dengan cara lain perusahaan dapat menggunakan prinsip Loss Aversion. Dengan menerapkan prinsip Loss aversion pada perusahaan maka dapat membedakan cara pembagian komisi produk. Perusahaan A melakukan pembayaran komisi dimuka, sehingga setiap terjadi penjualan ia akan mengambil sebagian komisi dan pada akhirnya akan mengembalikan komisi sisa dari produk yang tidak terjual. Sedangkan B membayar diakhir sesuai dengan jumlah penjualan yang terjadi. Misalkan komisi produk B adalah $\$ 12$ sedangakan A adalah \$10. Secara rasional jika pelanggan datang maka seharusnya penjual akan cenderung menjual produk B sehingga yang terjadi adalah net \$2. Mempertimbangkan \$ 10 harus dikembalikan ke perusahaan A. Pada eksperimen ini yang terjadi adalah kecenderungan para penjual untuk menjual secara berlebih (overselling) produk A. Kecenderungan orang untuk mempertahankan uang (komisi dibayar dimuka) lebih tinggi walaupun secara rasional perhitungannya tidak demikian. Keuntungan \$ 2 jelas tidak dihiraukan. Kehilangan \$ 10 lebih menyakitkan. Contoh lain lagi adalah jika seorang karyawan bekerja pada sebuah perusahaan dan setiap bulan karyawan tersebut dapat menyisihkan uang untuk dana pensiunnya. Biasanya karyawan dan manajemen akan melakukan 
sinkronisasi. Jika karyawan akan menyisihkan $5 \%$ maka manajemen juga melakukan dengan persentase yang sama. Sehingga $10 \%$ akan berada pada dana pensiun. Bagaimana agar karyawan dapat melakukan saving lebih banyak? Penggunaan prinsip loss aversion dapat berperan. Perusahaan dapat menukar proses kerjanya dengan cara memberikan dimuka 10\%, lalu jika karyawan akan memasukan 5\% dana pensiunnya maka dengan proses match perusahaan akan mengurangi $10 \%$ tersebut menjadi hanya $5 \%$ sehingga karyawan merasakan kehilangan (loss aversion) 5\%. Eksperimen yang terjadi mengungkapkan karyawan akan menggenapkan menjadi $10 \%$ agar tetap tersinkronisasi dengan perusahaan.

\section{Endowment Effect}

Salah satu heuristic adalah Endowment Effect, merupakan kecenderungan seseorang untuk mempertahankan atau memberi nilai (harga) lebih mahal pada barang yang telah ia miliki dibandingkan dengan sebelum ia memiliki barang tersebut. Knetsch dan Sinden (1984) melakukan eksperimen dari endowment effect terhadap beberapa orang partisipan. Para partisipan diberikan tiket lotre atau uang sejumlah $\$ 2$. Setiap subjek partisipan diberi kesempatan untuk menukar tiketnya dengan uang atau sebaliknya. Hasilnya, banyak partisipan yang memegang tiket tidak menukarkan tiketnya dengan uang. Ini berarti pemegang tiket sepertinya lebih menyukai tiketnya dibandingkan orang yang memegang uang. Untuk menerangkan endowment effect secara lebih terperinci terdapat eksperimen dengan produk "cangkir". Terdapat 2 kelompok, kelompok A dan B. Kelompok A adalah orang orang yang diberi cangkir dan kelompok B adalah orang yang tidak memiliki cangkir. Secara rasional dalam menilai berapa harga cangkir tersebut kedua kelompok haruslah memiliki harga yang relatif sama antara pembeli dan penjual. 


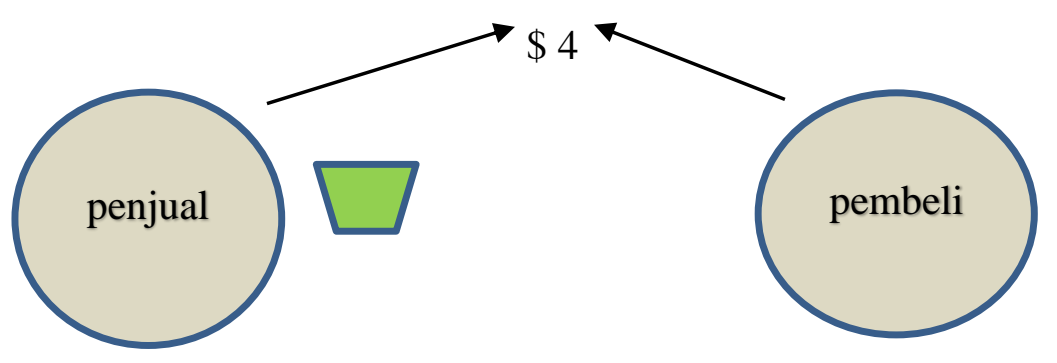

Gambar 1 Ekpektasi rasional.

Individu rasional tidak terlalu ada sama Ketika kelompok A dan B perbedaan berarti dalam penilaian bertukar peran. Cangkir itu tidak cangkir (hijau) namun kenyataannya mempengaruhi perilaku Ketika belum dapat berbeda karena penjual memiliki dimiliki. Lain halnya setelah dimiliki valuasi lebih tinggi dibanding pembeli. (endowment).

Hal ini tetap mempunyai hasil yang
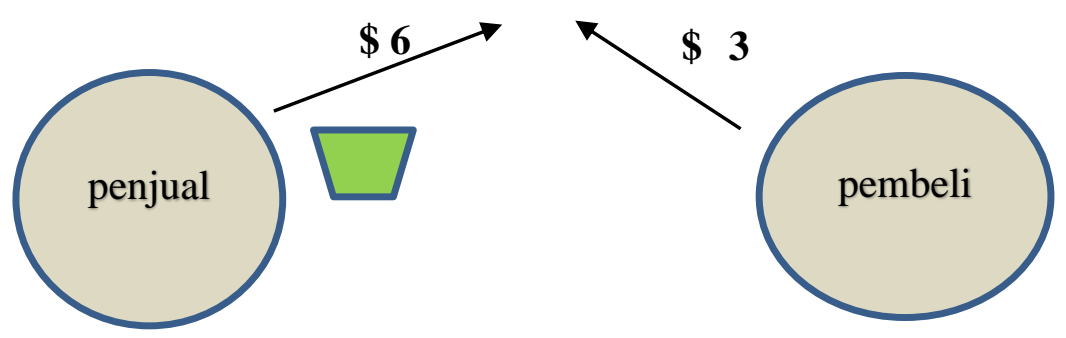

Gambar 2 Endowment effect terjadi perbedaan harga karena kepemilikan

dari gambar tersebut terjadi ada perbedaan harga karena kepemilikan lebih jauh lagi, jika diberikan mug kepada kelompok penjual dan pembeli maka pembeli pun menaikkan harga dari mug tersebut, dimana harga mug tersebut mendekati harga dari penjual 


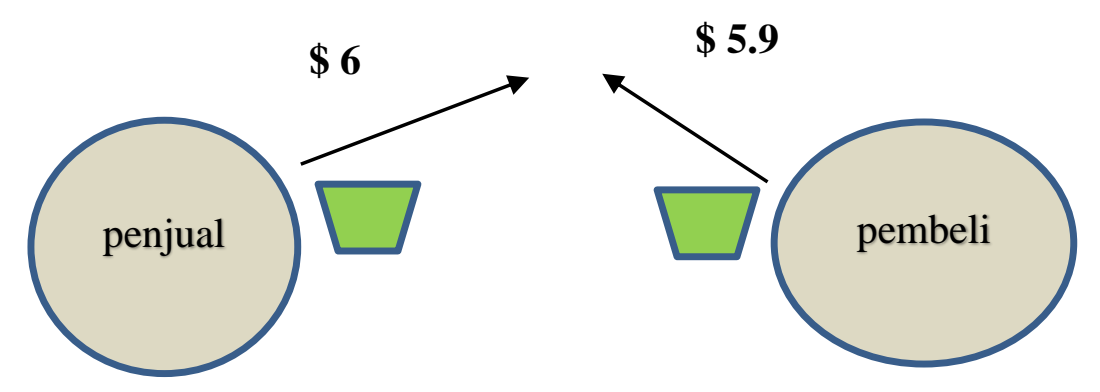

Gambar 3 keduanya memiliki cangkir endowment effect berkurang

Keduanya memiliki cangkir endowment effect berkurang, Sedangkan jika keduanya tidak memiliki maka harga keduanya masih berdekatan namun keduanya menilai lebih rendah.

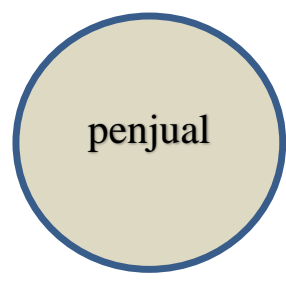

\$3.10

\$3

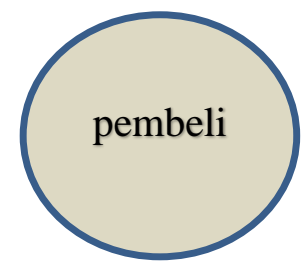

Gambar 4 Keduanya tanpa cangkir

Kahneman, knetcsh dan thaller (1999) melakukan serangkaian eksperimen, untuk menentukan apakah endowment effect masih terlihat jika pelakunya berhadapan dengan situasi pasar (market dicipline) dan mempunyai kesempatan untuk belajar. Eksperimen yang pertama, beberapa mahasiswa dari cornell university berpartisipasi dalam serangkaian kegiatan eksperimen pasar. Terdapat 3 pasar dengan produk berbeda yang dilakukan pengaturan dalam kegiatannya. Pasar yang pertama menggunakan "token" sebagai produknya. Pada pasar tersebut setiap orang diberi informasi pentingnya token dan dilakukan pembagian token kepada setiap orang dengan jumlah berlainan. Sebagian dari mahasiswa diberi token dan sebagian lagi tidak. Dengan cara ini permintaan dan penawaran token akan terbentuk. Subyek berganti peran secara bergiliran baik sebagai pembeli ataupun penjual. Mereka melakukan 3 kali. Pada pasar ini tidak terjadi anomali, harga kliring token relatif sama dengan harga keseimbangan pasar dari permintaan dan penawaran. Untuk memodifikasi eksperimen tersebut, segera setelah token maka subyek diberi sebuah 
cangkir yang dijual dengan harga $\$ 6$. Eksperimen dilakukan dengan melakukan 4 pasar untuk cangkir tersebut dengan prosedur yang sama terkecuali 2 aturan tambahan. Aturan tambahan yang pertama adalah satu dari empat pasar yang dilakukan akan dipilih secara acak dan hanya perdangan cangkir dipasar terpilih inilah akan dieksekusi. Aturan kedua pada pasar tersebut seluruh transaksi akan diimplementasikan. Hal ini dilakukan agar subjek memiliki kesempatan untuk belajar. Hasil yang terjadi menyatakan bahwa endowment efect masih terlihat dengan median harga jual dua kali daripada harga beli. Implementasi endowment effect dalam kehidupan terlihat sangat nyata. Bagaimana suatu barang dicoba ditayangkan didepan anda. Tidak hanya ditayangkan tetapi dibuat seolah-olah anda dapat merasakan keberadaannya dengan sangat personal. Bank and Olufsen adalah perusahaan audio yang mempergunakan kustomisasi visual pada websitenya agar pelanggan dapat merasakan produknya sehingga terasa memiliki. Contoh sederhana lain adalah fitting room. Pelanggan mencoba baju dan merasakan bahwa bajunya telah cocok dan sulit untuk berkelit dari jeratan rasa memiliki.

\section{Status Quo Bias}

Individu membuat keputusan-keputusan dalam kehidupan sehari-hari. Asumsi yang sering dianggap benar adalah jika seorang individu membuat keputusan berdasarkan preferensi sendiri. Makanan yang disuka dipilih karena memberikan utilitas atau kepuasan tertinggi bagi diri sendiri. Namun penelitian membuktikan, apa yang seseorang pilih sering kali dipengaruhi oleh serangkaian faktor eksternal. Sejumlah eksperimen membuktikan hal ini. Salah satunya adalah eksperimen yang dilakukan oleh Universitas Cardiff. Sebuah tempat dipersiapkan di mana peserta relawan penelitian (subjek) dapat melempar bola kedalam keranjang dari jarak beberapa meter layaknya seperti permainan dalam pasar malam. Didepan keranjang adalah sebuah kamera yang dipasang untuk merekam aksi yang terjadi. Supaya orang tertarik mengikuti eksperimen ini, disediakan hadiah makanan kecil (coklat batangan). Diinformasikan juga jika berhasil memasukan sebuah bola kedalam keranjang menggunakan tangan yang dominan (DH) maka 
mendapatkan satu buah coklat, sedangkan jika menggunakan tangan

\section{METODOLOGI PENELITIAN}

Metode penelitian yang digunakan penulis dalam hal ini menggunakan studi literatur dengan cara menghubungkan satu literatur dengan literatur lainnya sebagai dasar untuk berdebat, dan untuk tinjauan yang lebih dalam. Di dalam ekonomi DH mewakili orang-orang yang mempunyai preferensi risiko lebih rendah dibanding dengan NDH. Prinsip high risk high return diterapkan pada eksperimen ini. Secara acak subyek dibagi dalam dua grup. Grup yang pertama adalah grup yang mewakili low risk low return. Artinya ia melempar menggunakan DH (sebagai "default") dan mereka ditawarkan untuk dapat mengganti menggunakan NDH dengan hadiah yang lebih banyak. Grup yang kedua $\mathrm{NDH}$ (default) ditawarkan untuk mengganti menjadi DH. Eskperimen ini berusaha melihat apakah subjek membuat keputusan secara logis dengan melihat bobot antara risk dan reward, atau membuat keputusan berdasarkan bagaimana informasi ini disajikan. Pada eksperimen ini hasil yang diharapkan sebelumnya adalah pada kelompok yang tidak dominan (NDH) maka dua buah coklat diberikan.

pertama dan kedua subyek yang melempar dengan DH atau NDH pasti akan lebih banyak jumlahnya disalah satu sisi. Namun kenyataannya, pada kelompok pertama, orang tidak nyaman untuk merubah menjadi NDH tetap pada default sedangkan, di kelompok kedua orang pun tetap pada default. Ini berarti para subjek tidak merasa nyaman jika mengubah keputusan mereka untuk beralih dari default. Inilah yang disebut status quo bias. Argumen ini sesuai dengan prinsip loss aversion bahwa secara psikologis seseorang merasa rugi berkali lipat jika merubah default dibanding dengan mempertahankannya. Suatu tes adanya status quo juga dilakukan oleh Hartman, Doane, Woo yang menggunakan perusahaan listrik California. Konsumen diminta untuk menjawab pertanyan mengenai keandalan pelayanan dan harga listrik. Para partisipan diberi informasi bahwa jawabannya akan mempengaruhi kebijakan perusahaan dimasa depan. Pertanyaan didisain sedemikian rupa sehingga salah satu kombinasinya adalah pernyataan status quo nya. Hasilnya tetap konsisten bahwa setiap 
peserta mempunyai kecenderungan untuk memilih status quo. Status quo bias sangat mempengaruhi keputusan dalam kehidupan sehari-hari. Tidak membeli produk asuransi karena kerepotan atau ketakutan akan

\section{SIMPULAN DAN SARAN}

Heuristic selalu terjadi pada individuindividu dalam mengambil keputusan manajemen. Seringkali tidak terhindarkan Daniel Kahneman menyarankan bahwa individu dalam mengambil keputusan manajemen tidak terjebak pada suatu pemikiran yang sudah terbentuk tapi membutuhkan

\section{DAFTAR PUSTAKA}

Ackert, L. F., \& Deaves, R. (2009). Behavioral

Finance:

Psychology, Decision making and Market Independence. Cengage Learning.

Amelie, C., Darne, O., \& Kim, J. H. (2017). Adaptive Markets Hypothesis for Islamic Stock Indices: Evidence from Dow Jones Size and Sector-Indices. International Economics, 100112.

bruner, J., Calegari, F., \& Hanfield, T. (2020). evolution of Endowment Effect. Evolution and Human Behavior.

Ciumara, T. (2014). Factor Influencing Individual Financial Decision : A Literature Review. GIDNI. Research Gate. investasinya. Selalu memesan menu yang sama dalam satu rumah makan. Selalu memakai teknik yang sama dalam berinvestasi padahal banyak teknik lain yang lebih maju.

dekonstruksi konsep lagi agar lebih dapat berpikir secara rasional. Thinking Slowly lebih tepatnya sehingga awareness terhadap setiap masalah dapat lebih jelas. Menyadari bahwa faktor eksternal dapat menjadi pengaruh terhadap proses pengambilan keputusan.

Coursey, D. L., Hovis, J. L., \& Schulze, W. D. (1987). The Disparity Between Willingnes to Accept and Willingness to Pay Measure of Value. (pp. 679 - 90). Quarterly Journal of Economic.

Farandy, A. (2019). Pengaruh Kepemimpinan Transaksional dan Kompensasi terhadap Motivasi Kerja dan Dampaknya pada Kinerja Karyawan PT. Indo Acidatama Tbk. Jurnal Bina Manajemen.

Feby, T. (2019). Pengaruh Kualitas Pelayanan Mitra Gojek Terhadap Loyalitas Pelanggan dengan Kepuasan Pelanggan sebagai Variabel Mediasi. Journal Bina Manajemen.

Kahneman, D., \& Tversky, A. (1979). Prospect Theory : An Analysis of Decision Under Risk. (pp. 263-291). Econometrica. 
Kahneman, D., \& Tversky, A. (1991). Loss Aversion and Riskless choice: A Reference Dependent Model. quarterly Journal of Economics.

Kahneman, D., Knetsch, J. L., \& Thaler, R. (1990). Experimental Test of The Endowment Effect and Coase Theorem. (pp. 1325 1348). Journal of political economy.

Kahneman, D., Knetsch, J. L., \& Thaler, R. H. (1991). Anomalies The Endowment Effect, Loss Aversion, and Status Quo Bias. Journal of Economic Prespectives, 5(winter 1991), $193-206$.

Lo, A. W. (2017). Adaptive Market. New Jersey: Princeton University Press.

Nurhalim, A. D. (2020). An overview of the development Electronic
Wallet in Encouraging Economic Growth in Indonesian Teritory. Primanomics.

Oktafalia Marisa, J. R. (2020). Pengaruh Price Fairness terhadap Repurchase Intention High End Make Up dan Skin Care pada Generasi Milenial Di Jakarta. Jurnal Bina Manajemen.

Shiller, J. R. (2000). Irrational Exuberance. New Jersey: Princeton University Press.

Thaler, R. H. (1988). Anomalies : The Winners Curse (Vol. 2). Journal of Economic Perspective.

Thaler, R. H. (2016). Misbehaving : The Making of Behavioral Economic. W.W. Norton \& Company. 